\title{
Selecting Locations of Electric Vehicle Charging Stations Based on the Traffic Load Eliminating Method
}

\author{
Bong-Gi Choi ${ }^{1}$, Byeong-Chan Oh ${ }^{1} \mathbb{D}$, Sungyun Choi ${ }^{2} \mathbb{D}$ and Sung-Yul Kim ${ }^{3, *}$ \\ 1 Department of Electronic and electrical Engineering, Keimyung University, 1095 Dalgubeol-daero, \\ Daegu 42601, Korea; cbg1161@gmail.com (B.-G.C.); obchan08@naver.com (B.-C.O.) \\ 2 School of Electrical Engineering, Korea University, 145 Anam-ro, Seongbuk-gu, Seoul 02841, Korea; \\ sungyun@korea.ac.kr \\ 3 Electrical Energy Engineering, Keimyung University, 1095 Dalgubeol-daero, Daegu 42601, Korea \\ * Correspondence: energy@kmu.ac.kr; Tel.: +82-53-580-5251
}

Received: 7 February 2020; Accepted: 30 March 2020; Published: 2 April 2020

\begin{abstract}
Establishing electric vehicle supply equipment (EVSE) to keep up with the increasing number of electric vehicles (EVs) is the most realistic and direct means of promoting their spread. Using traffic data collected in one area; we estimated the EV charging demand and selected priority fast chargers; ranging from high to low charging demand. A queueing model was used to calculate the number of fast chargers required in the study area. Comparison of the existing distribution of fast chargers with that suggested by the traffic load eliminating method demonstrated the validity of our traffic-based location approach.
\end{abstract}

Keywords: electric vehicle supply equipment (EVSE); charging station; electric vehicle; traffic; Kriging; location; queueing model

\section{Introduction}

The growing number of electric vehicles (EV) raises many concerns about EV supply equipment (EVSE) [1]. In particular, the fact that the number of EV charging stations is not keeping up with the increase in the number of EVs is the greatest problem for consumers who are considering buying EVs [2]. While government funding and investment are prerequisites for the expansion of EVSE, academic studies should also provide methods that enable EVSE to be cost effective [3-9]. In this context, many studies are being conducted on selecting EVSE locations across cities in Korea [10-20]. However, the analysis of EV charging demands must precede the selection of EVSE locations. To analyze charging demands, many researchers have used big data collected in various ways, including origin-destination (OD) data collected from information-gathering devices mounted on EVs and EV chargers, traffic data collected from traffic-information-gathering sections in cities, as well as sectoral data accumulated by Statistics Korea. Although using OD data from large numbers of vehicles and state of charge (SOC) data to analyze EVSE locations would produce the most objective and reasonable conclusions, it is not easy to acquire such data officially in ordinary studies. Hence, we suggest using the traffic load eliminating method (TLEM) to select locations for EV fast charging infrastructure, based on easily accessible traffic data as well as driving data for the area monitored by Statistics Korea.

Charging demands are highly correlated with traffic [21]. As such, it is possible to identify overall charging demands if data are available regarding the distribution of traffic in the area. However, traffic analysis only indicates the presence of charging demand in the area and cannot show the exact number of chargers needed in the area. In the present study, the number of chargers needed in a particular area 
was calculated using a queueing model that reflects driving statistics in the area. Figure 1 illustrates the process utilized for priority charger selection in the present study.
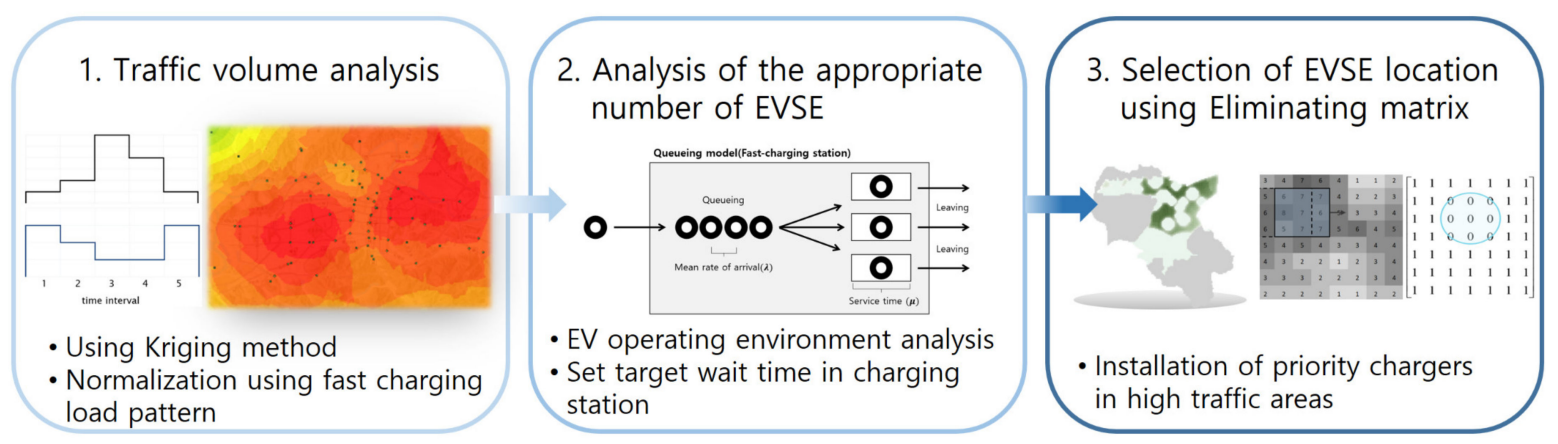

Figure 1. Process of estimating fast charging demand and selecting priority chargers.

- First, since traffic data collectors were not installed in all parts of the study area for traffic analysis, it was necessary to estimate the amount of traffic at the points at which traffic data were not collected based on the traffic at the points at which traffic data were collected. For this purpose, the Kriging technique was used to quantify the traffic all across the study area. To normalize the traffic map, which was used in the charging demand analysis, we used traffic data and fast charging patterns collected on an hourly basis.

- Second, the daily number of EVs requiring charging was analyzed using statistical traffic data accumulated in the study area, and the estimated demand was utilized to establish a queueing model. Following this step, the required number of fast chargers $(\mathrm{N})$ was analyzed.

- Finally, the quantified traffic map was converted into a matrix, and the eliminating matrix was used to select a priority charger. This process was repeated $\mathrm{N}$ times.

The remainder of this paper is organized as follows. Section 2 provides an analysis of traffic based on the Kriging technique. Section 3 describes the utilization of the queueing model and calculation of the number of fast chargers required in the study area. Section 4 suggests a method that facilitates the selection of priority fast chargers based on the eliminating matrix. Next, Section 5 presents a case study. Finally, Section 6 summarizes the conclusions.

\section{Estimation of Expected Charging Demand}

In this study, since the traffic volume was utilized as an indicator of the fast charging demand of EVs, it was necessary to reflect the hourly traffic volume change at the target site fully in the expected charging demand calculation.

\subsection{Site Gridding}

A grid-type expression was required to indicate traffic volume information on a two-dimensional coordinate plane for traffic volume analysis at the target site, including spatial information. In this study, the traffic volume of the target site was expressed as a matrix using the coordinate plane consisting of $i$ and $j$ axes, as shown in Figure 2. In this case, the narrower the interval between grids, the more detailed the traffic volume information that can be included. 


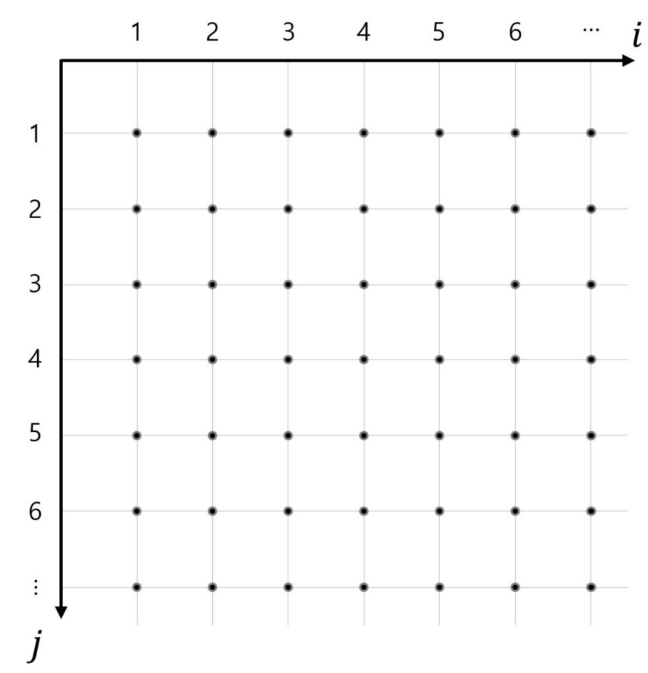

Figure 2. Two-dimensional grid.

\subsection{Estimation of Expected Charging Demand Using Kriging Technique}

To use the traffic volume as an indicator of the fast EV charging demand, it was necessary to obtain traffic data throughout the site.

In most parts of the study area, however, the traffic data gathering sections were not located densely enough for us to acquire traffic data throughout the area. Due to the maintenance cost of traffic data gathering sections as well as the need for efficiency in terms of not having to manage vast amounts of traffic data, cities typically use affordable numbers of traffic data collectors to promote the underlying industry or transport system.

Since traffic data all across the study area were required to analyze the EV charging demand, we used the Kriging technique to estimate the amounts of traffic at points without any traffic data, based on the data collected by traffic data collectors in the study area [22]. The Kriging technique is based on the geographic information system (GIS), which estimates the value for a non-measured point from a linear combination of values for the surrounding measured points. The technique was named after D.G. Krige, a mining engineer in South Africa, who developed the empirical technique in the 1950s to determine the optimal distribution of mineral grades from sampled mineral grades. The Kriging technique is often used to estimate or interpolate values that are difficult to measure, such as those corresponding to air quality or natural gas deposits in environmental engineering and geographic engineering. To use the Kriging technique, we followed the procedure depicted in Figure 3 in this study.

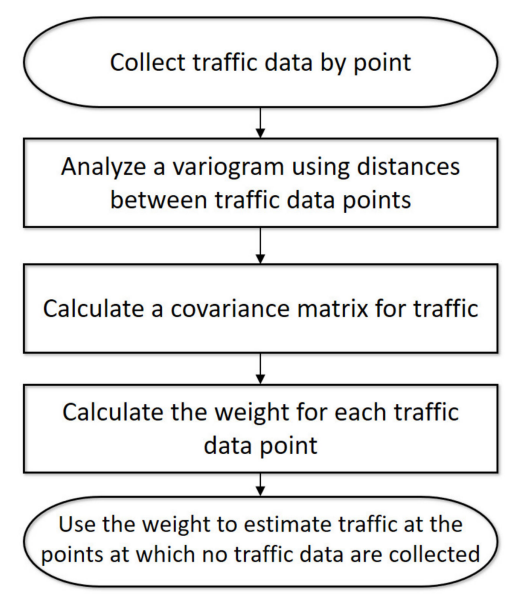

Figure 3. Flow chart of the Kriging technique. 
Firstly, the traffic data collected in the study area are represented in a variogram to indicate their distributed distances. Based on the distances between the collected traffic data, a covariance matrix is calculated to obtain the weights of given points for observation. After obtaining the weights, the weighted average is used to estimate the amounts of traffic at the given points.

Twenty-four-hour traffic data collected every hour were used to visualize the traffic all across the study area based on the Kriging technique. However, values could be estimated even if there was actually no value at a given point due to the nature of the Kriging technique. Hence, the values estimated for zones such as mountains and rivers that vehicles cannot enter, as well as industrial complexes where there is almost no traffic, were eliminated from this study. From the traffic matrix predicted using the Kriging technique, the forecast produced in areas where traffic rarely occurs was eliminated, thus producing a traffic matrix describing only areas where traffic actually occurs.

Figure 4 depicts $T L_{t}^{E}$ and $T L_{t}^{U}$. Although the amount of traffic was estimated by the Kriging technique throughout the study area, Figure 4 is shaded in areas in which there is almost no active traffic. $T L_{t}^{U}(i, j)$ means the amount of traffic estimated in zones such as mountains and rivers where there is almost no traffic. $T L_{t}^{E}$ is the amount of traffic obtained by subtracting the amount of traffic in zones with almost no traffic from $T L_{t}^{A}$, the total amount of traffic in the study area.

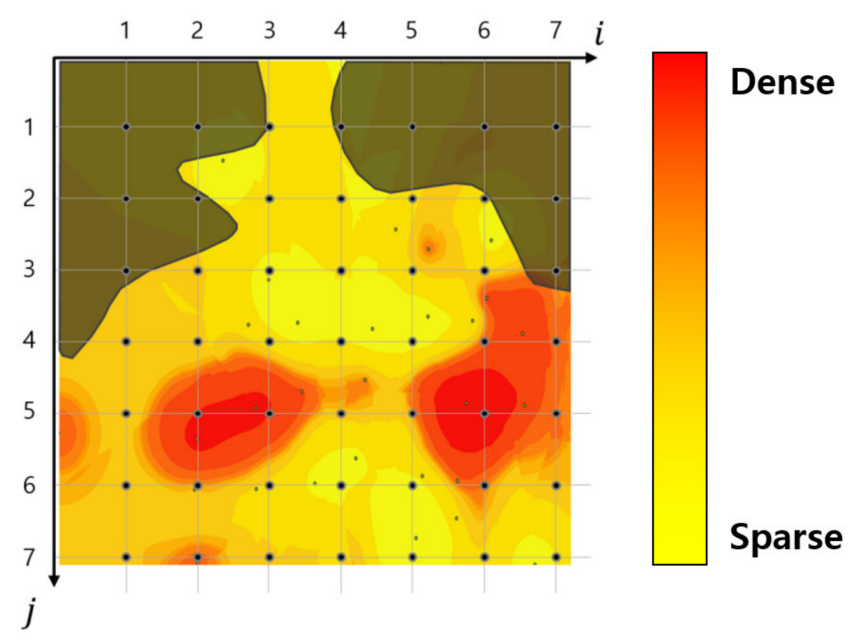

Figure 4. $T L_{t}^{E}$ and $T L_{t}^{U}$ in the study area.

\subsection{Expected Charging Demand Normalization Using Fast Charging Load Pattern}

It is necessary to analyze fast charging demand to select the locations of fast chargers. Since the amount of traffic was utilized to determine the expected charging demand in this study, it was critical to analyze traffic. Traffic data collectors gather traffic data per minute or hour. As the amount of traffic increases or decreases along with events of the day such as rush hours, it was important to determine which hours of traffic data would be more efficient to use. To determine such hours, we employed hourly fast charging load patterns from users. The fast charging demand does not necessarily increase even if there is a lot of traffic. For instance, the fast charging demand at noon is usually higher than that during the morning rush hours, which produce the largest amount of traffic in a day. As a result, traffic information needs to be analyzed in more detail to select reasonable fast charge demands. Traffic volume varies with time. Therefore, by combining hourly traffic with hourly fast charging demand, we intended to calculate the amount of charge demand that was representative of the target area that could be understood at all times. Therefore, it was important to reflect the hours of traffic that create more demand for fast charging and to normalize such traffic to enable priority fast charger selection.

To clarify the points mentioned above, we would like to describe the following example. By multiplying the traffic volume and the fast charge load for each time zone and adding them for all times, the fast charge demand value of the target site can be normalized. The total traffic for Site A in the study area (highlighted in red in Figure 5) is 8, lower than that at Site B, but its traffic 
is concentrated in the hours during which there is the greatest demand for fast charging. Therefore, the expected charging demand for Site A ( 32 in this example) is higher than that for Site B (21 in this example). In addition, the total traffic at Site B (highlighted in blue in Figure 5) is 11, higher than that at Site A, but the traffic at the former site is lower during the hours during which there is the most demand for fast charging. Hence, the expected charging demand for Site B is lower than that for Site A. We converted the hourly fast charging patterns into hourly weights and multiplied these by the hourly amounts of traffic in the study area to calculate the traffic-based expected charging demand, which was used for priority fast charger selection.

Site A
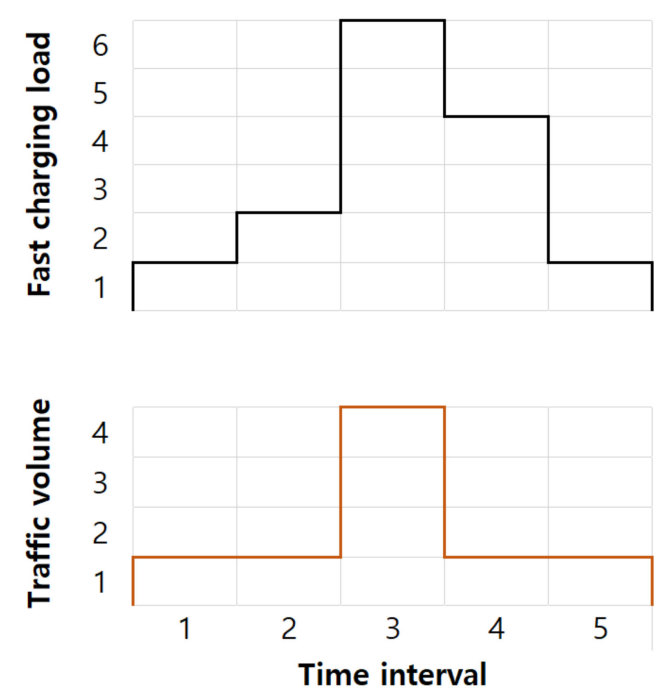

\section{Site B}
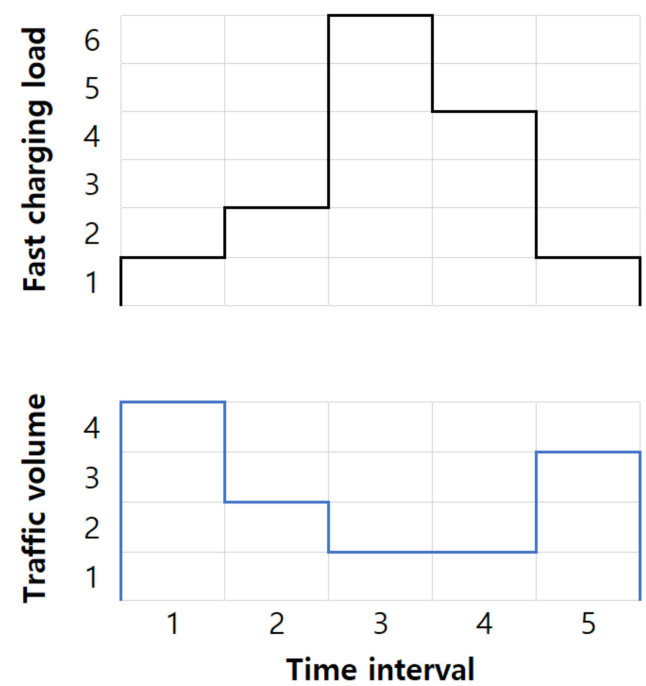

Figure 5. Example of hourly fast charging patterns and traffic.

Equations (1) to (6) below reflect the hourly traffic and fast charging patterns in the zone in which active traffic arises and were used to normalize the amount of traffic in the study area, which was then used for priority fast charger selection:

$$
\begin{gathered}
T L_{t}^{E}(i, j)=T L_{t}^{A}(i, j)-T L_{t}^{U}(i, j) \\
T L_{t}^{E \_ \text {sum }}=\sum_{\forall i, j} T L_{t}^{E}(i, j) \\
T L^{E \_ \text {sum }}=\sum_{\forall t} T L_{t}^{E \_ \text {sum }} \\
F C=\sum_{\forall t} F C_{t} \\
T L^{\text {Norm }}(i, j)=\sum_{\forall t}\left(\frac{F C_{t}}{F C} \times \frac{T L_{t}^{E \_ \text {sum }}}{T L^{E \_ \text {sum }}} \times T L_{t}^{E}(i, j)\right) \\
T L=\sum_{\forall i, j} T L^{N o r m}(i, j)
\end{gathered}
$$

Figure 6 summarizes how expected charging demand is normalized: 


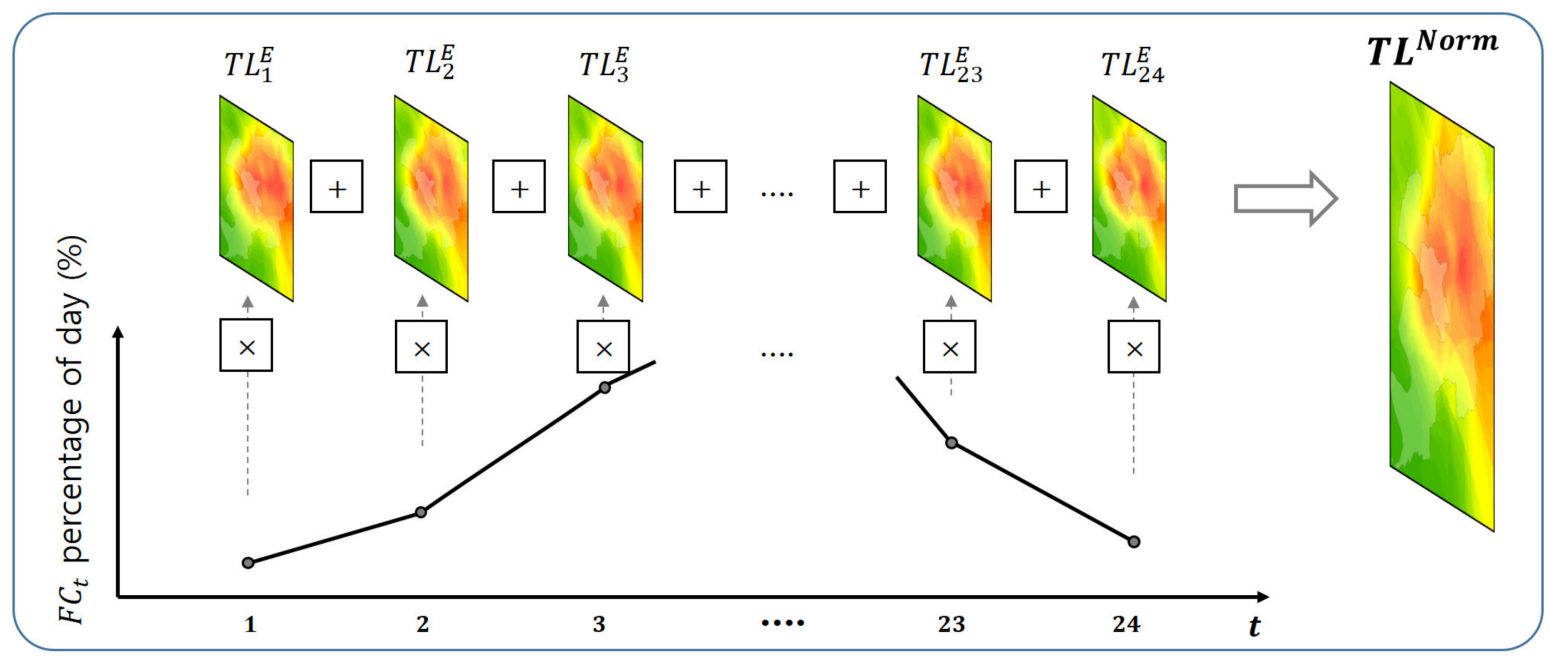

Figure 6. The process of normalizing expected charging demand.

\section{Analysis of the Statistically Optimal Number of Chargers Based on the Queueing Model}

\subsection{Characteristics and Structure of Queuing Model}

Section 2 described the charging demand by zone based on the normalized amount of traffic. To satisfy this visualized charging demand, it is necessary to determine the number of chargers installed and supplied. This section describes the use of the queueing model to analyze the optimal number of chargers in the study area. The queueing model determines the cost-effective service capacity and scale necessary to maintain the optimal level of waiting once a user arrives at a fast charging station. This analytical method accounts for the waiting time in the queueing matrix and the charging demand and is widely used in the field of service infrastructure, including urban planning.

The queueing model can analyze the waiting time for charging depending on the number of chargers installed at a charging station. It enables analysis of the number of chargers at each charging station that satisfies the target waiting time per user and identification of the total optimal number of chargers in the study area. The queuing model used is a simple $\mathrm{M} / \mathrm{M} / \mathrm{c}$ model. Since statistical data such as the number of EVs arriving at the fast charging station per hour and the time spent by one fast charger charging one EV were used, an M/M/c model was employed so that the distribution of arrival frequency and service time followed the Poisson distribution. As the service type of the rapid charger is a method in which all the chargers provide the service to the user in parallel, the chargers determined that the $\mathrm{M} / \mathrm{M} / \mathrm{c}$ type would be ideal, where the chargers were independent and the same multiple chargers were added.

Figure 7 illustrates the structure of the queueing model considered in this study.

$$
\begin{gathered}
\rho=\frac{\lambda}{s \mu} \\
P_{0}=\frac{1}{\left[\sum_{n=0}^{s-1} \frac{1}{n !}\left(\frac{\lambda}{\mu}\right)^{n}\right]+\frac{1}{s !}\left(\frac{\lambda}{\mu}\right)^{s}\left(\frac{1}{1-\rho}\right)} \\
L_{q}=\frac{P_{0}\left(\frac{\lambda}{\mu}\right)^{s} \rho}{s !(1-\rho)^{2}} \\
W_{q}=\frac{L_{q}}{\lambda}
\end{gathered}
$$




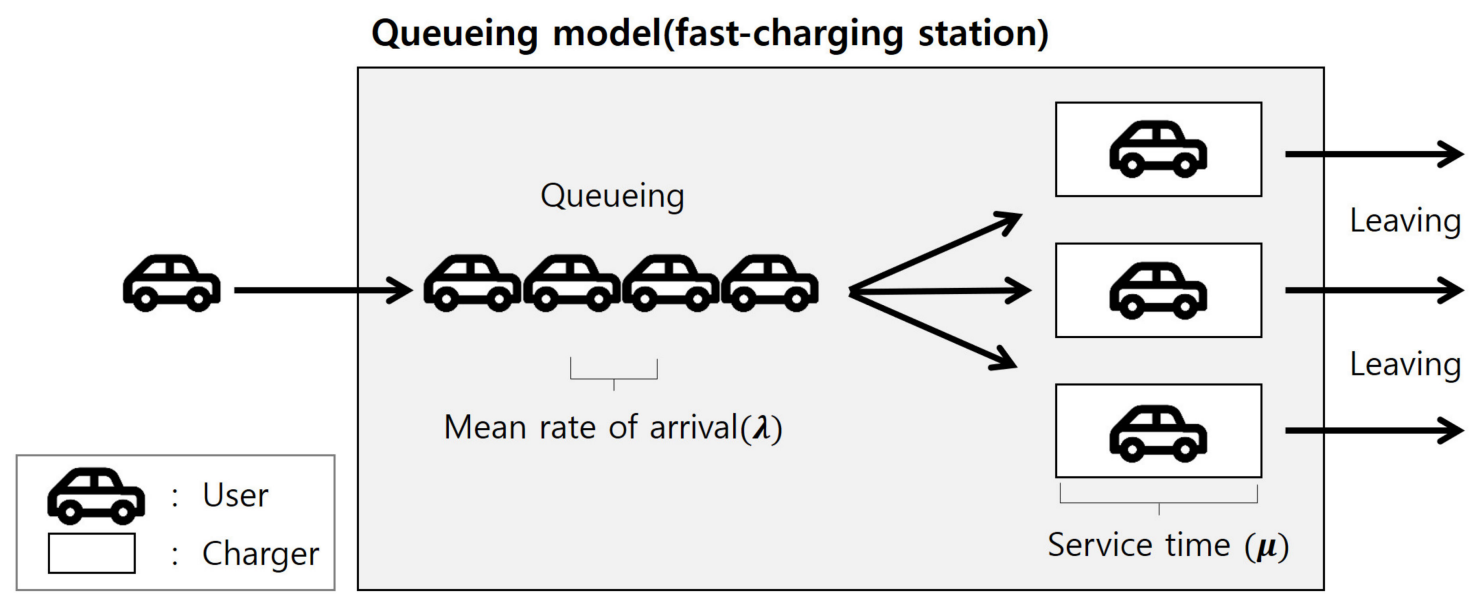

Figure 7. Example of queueing model application to a charging station.

Where $s$ means the number of chargers in the charging station, and $\mu$ refers to the service rate, and indicates how many EVs can be charged per hour; $\lambda$ is the arrival rate, which indicates the number of EVs entering the system per hour; $\rho$ is the utilization rate, which indicates the extent to which EVs use a fast charger. $P_{0}$ shows the probability that there is no user at the charging station; $L_{q}$ is the average number of users in the queueing matrix; $W_{q}$ is the average time spent in the queueing matrix. If $W_{q}$ is higher than the value set by the manager, it can be decreased by increasing the number of chargers.

To calculate the hourly number of arriving $\operatorname{EVs}(\lambda)$, which is a parameter in the queueing model, we used the mileage per charge, taking into account the average daily mileage of a passenger car, the types of car models with most EVs, and the EV fuel efficiency. This equation enables the statistical calculation of the number of users who visit fast charging stations in a day among the vehicles in the study area:

Number of EVs $=$ Total number of vehicles in the study area $\times$ EV penetration rate

$$
\lambda=\frac{\text { Average daily mileage } \times \text { Number of } E V s}{\text { Mileage per charge }}
$$

\subsection{Difinition of Objective Function Considering the Rrefueling System of Internal Combustion Engine} Vehicles

The queueing model analysis in the present study follows the below objective function and constraint:

$$
\begin{gathered}
N=\min \left(\sum_{\forall i} n_{i}\right) \\
\text { st. } t_{i} \leq\left. t_{o b j}\right|_{\forall i}
\end{gathered}
$$

Where $n_{i}$ is the number of chargers required to meet the target latency at the i-th station. Equation (13), which is an objective function, minimizes $N$ the total number of fast chargers at all of the charging stations in the area (i). Its constraint is that the number of chargers be set so that the waiting time of EVs for charging at all of the charging stations is less than or equal to that of the waiting time for internal combustion engine vehicles at gas stations. To achieve this objective, we analyzed the average waiting time at gas stations to set up a baseline waiting time for EVs. Since gas station infrastructure has been established and maintained for a very long time, we assumed the current infrastructure to be sufficient. Park (2007) reported that it took a total sample of 134 people $5.66 \mathrm{~min}$ to drive in and out of a gas station, and they filled their vehicles with $28.79 \mathrm{~L}$ of fuel on average per occasion. Hence, in this study, the average flow rate of a typical fuel nozzle was considered, $38 \mathrm{~s}$ was taken as the time during which fueling actually occurs after a fuel nozzle is inserted into the fuel tank, and the average waiting 
time for starting charge was estimated to be $5.02 \mathrm{~min}$ under the assumption that a vehicle leaves the gas station as soon as refueling is completed.

\section{Priority Charger Selection Based on the Eliminating Matrix}

Section 2 described the normalization of the traffic map, to be reflected in the priority charging station selection, and Section 3 presented the calculation of the total number of chargers required for the traffic map. This section discusses the use of the eliminating matrix to determine the optimal distribution of the number of chargers from Section 3 on the normalized traffic map from Section 2. The following steps were followed in the priority charger selection process based on the eliminating matrix:

- The total expected charging demand in the normalized study area and the total number of chargers from the queueing model were used to calculate the average expected charging demand that a charger should meet $(P)$;

- The eliminating matrix (supply range of charging station) was established in all cases that could exist within the target site (with $(i, j)$ as the charger location and $r$ as the supply radius);

- The eliminating matrix and charging station candidates meeting the constraints were selected;

- If the sum of the expected charging demands in the supply range of a priority charger was greater than $P$, extra expected charging demand was evenly added to the supply range to adjust for the difference;

- $\quad$ The above process was repeated $\mathrm{N}$ times.

To begin with, traffic in the study area normalized in Section 2 and the number of chargers calculated from the queueing model in Section 3 were used to estimate the average expected charging demand that a charger should satisfy:

$$
P=\frac{\sum T L}{N}
$$

$P$ calculated from Equation (15) was set as the basis for the range of service provided by a charger in the study area. If a single charging station was linked with multiple chargers, $P$ increased in proportion to the number of chargers. A zone with a higher expected charging demand could satisfy $P$ with a narrower search range than that of a zone with a lower charging demand. Hence, when the expected charging demand was higher, priority chargers were selected in a way that allowed them to be distributed more densely.

To identify priority charging stations that consider the level of expected charging demand, it was necessary to set up the eliminating matrix. For this purpose, we assumed there to be points with values of one outside the circle with $i$ and $j$ in $(i, j)$ being natural numbers, as in Figure 8. The value of points inside a circle with center $(i, j)$ and radius $r$ was set to zero. This set of point values was matched with the matrix $\mathrm{E}(i, j)$ to establish the eliminating matrix. The eliminating matrix can be expressed as follows:

$$
\begin{gathered}
E_{C(i, j, r)}(i, j)=\left\{\begin{array}{cc}
0, & \text { if inner }\left.C(i, j, r)\right|_{\forall i, j, r} \\
1, & \text { else }
\end{array}\right. \\
\text { optimal } L^{s}(i, j, r)=C(i, j, r) \text { where } \min (r) \\
\text { st. } P \leq \sum\left(T L(i, j)-\left(T L(i, j) \times E_{C(i, j, r)}(i, j)\right)\right)
\end{gathered}
$$




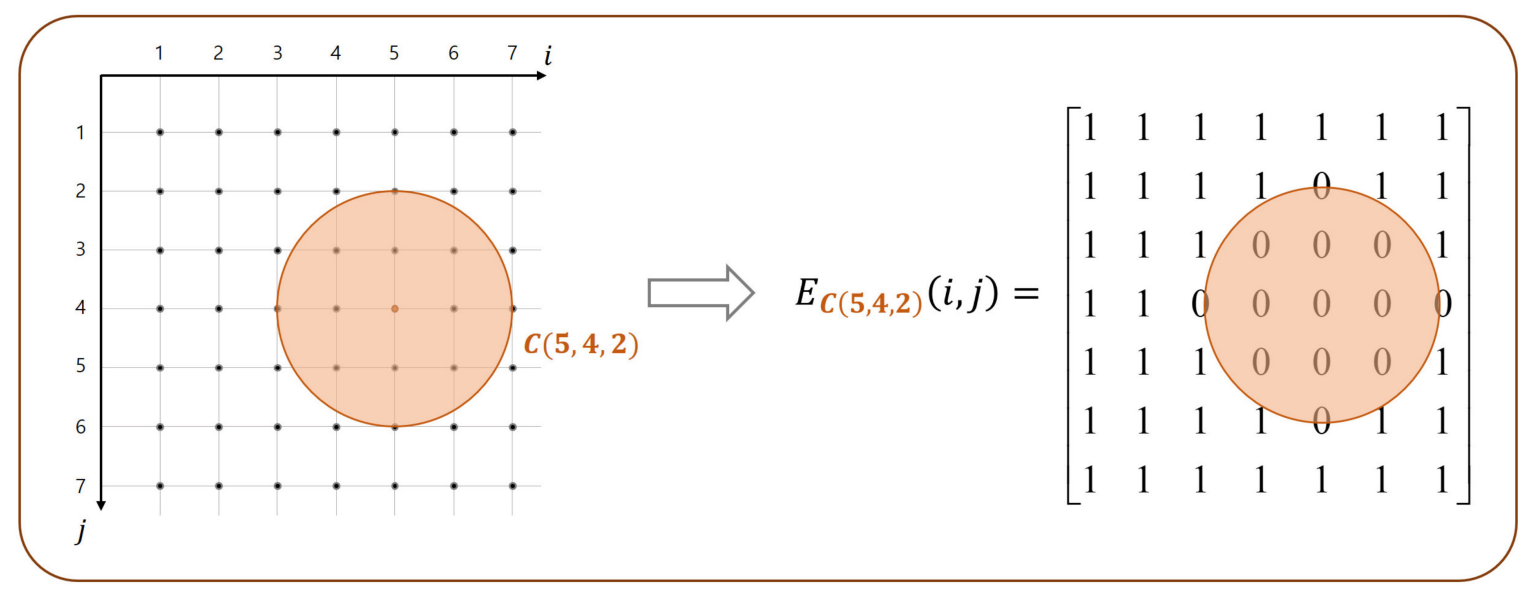

Figure 8. Establishing the eliminating matrix.

Equation (17), the objective function based on the eliminating matrix, calculates the optimal location of a charging station $L^{S}(i, j)$.To meet the expected charging demand that a charger should satisfy, the constraint in Equation (18) should be met. Among multiple search points that satisfy Equation (18) in a traffic map, which was used to analyze the location of the $s$-th charger, $C(i, j, r)$ with the lowest $r$ was set as the location of the $s$-th charging station $L^{s}(i, j, r)$, which means that the range of $C(i, j, r)$ with the lowest $r$ has the highest expected charging demand. Once the $s$-th priority charger was determined, the expected charging demand was reduced to zero as the expected charging demand in its range was considered to have received charging service. However, if the expected charging demand in the supply range of selected $s$-th charger was greater than $P$, the demand for the charge expected within the supply range was reduced to zero, and extra expected charging demand was evenly added to the supply range, thus ensuring that one charger accurately supplied the expected demand of $P$. Then, the $s+1$-th priority charger was searched. The compensation value that was evenly added to the supply range was calculated using Equation (19), where DN is the number of elements within the range of supply in the LS matrix. The expected charging demand used to select the location of the $s+1$-th priority charger was calculated using Equation (20):

$$
\begin{gathered}
C P_{L^{s}(i, j, r)}(i, j)=\left\{\begin{array}{l}
\frac{P-\sum_{i, j}\left(T L(i, j)-\left(T L(i, j) \times E_{L^{s}(i, j, r)}(i, j)\right)\right.}{D N_{L^{s}(i, j, r)}}, \text { if inner } L^{s}(i, j, r) \\
0, \text { else }
\end{array}\right. \\
T L^{s+1}(i, j)=T L^{s}(i, j) \times E_{L^{s}(i, j, r)}(i, j)+C P_{L^{s}(i, j, r)}(i, j)
\end{gathered}
$$

The optimal number of chargers $N$, which was calculated from the queueing model after repeating the above process, enabled the determination of the priority charger locations that met all of the charging demands in the study area.

Figure 9 illustrates a simple example of our suggested method of selecting the location of a fast charging station. The parameters used in this example included 240 as the total expected charging demand in the study area, with 4 being the optimal number of fast chargers calculated from the queueing model, and 60 being the expected charging demand that a fast charger should meet. 

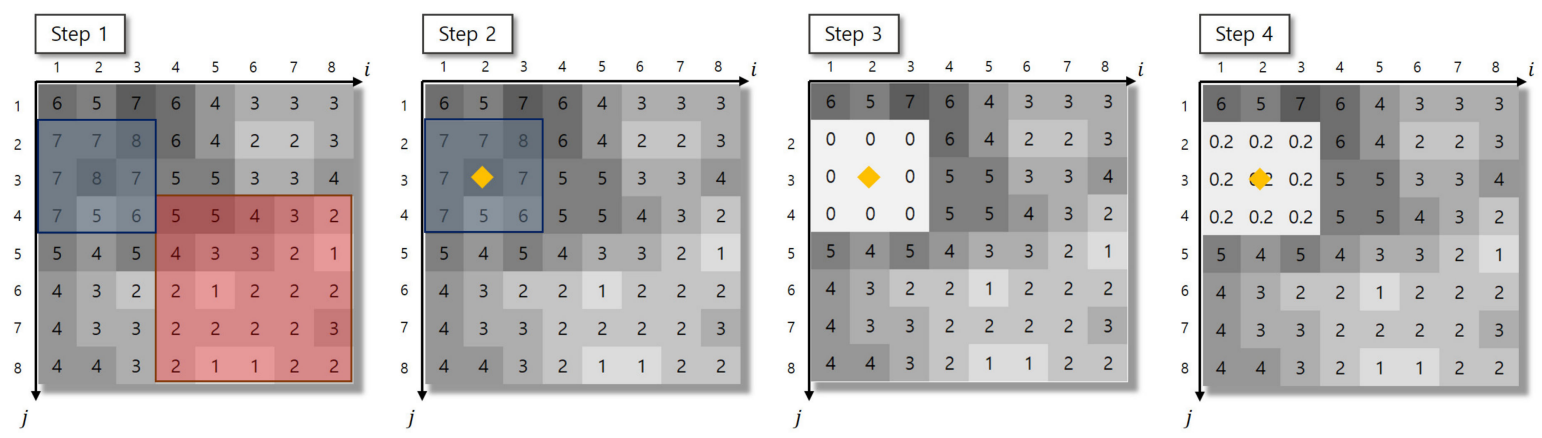

Figure 9. Example of establishing the eliminating matrix.

Step 1: The eliminating matrix $E_{C(i, j, r)}(i, j)$ was used for $T L(i, j)$ in the study area and all of the points that satisfied Equation (17) were searched. The blue and red ranges with expected charging demands of 62 and 60, respectively, were explored.

Step 2: $C(i, j, r)$ with the lowest $r$ from the points searched in Step 2 was selected as the priority fast charging station $L^{s}(i, j, r)$. Therefore, the blue range with the smallest search range $r$ was chosen as the candidate site for the $s$-th fast charging station.

Step 3: The expected charging demand in the supply range was removed for $L^{S}(i, j, r)$ out of the traffic $T L(i, j)$.

Step 4: The expected charging demand eliminated in Step 3 totaled 62, exceeding P by 2. Therefore, we divided the excess by DN (number of elements in the blue range) and added the compensation value from Equation (19).

Consequently, priority fast chargers were densely located in the zone with a higher expected charging demand, while all of the expected charging demand was met in the study area. The flow chart in Figure 10 illustrates this process.

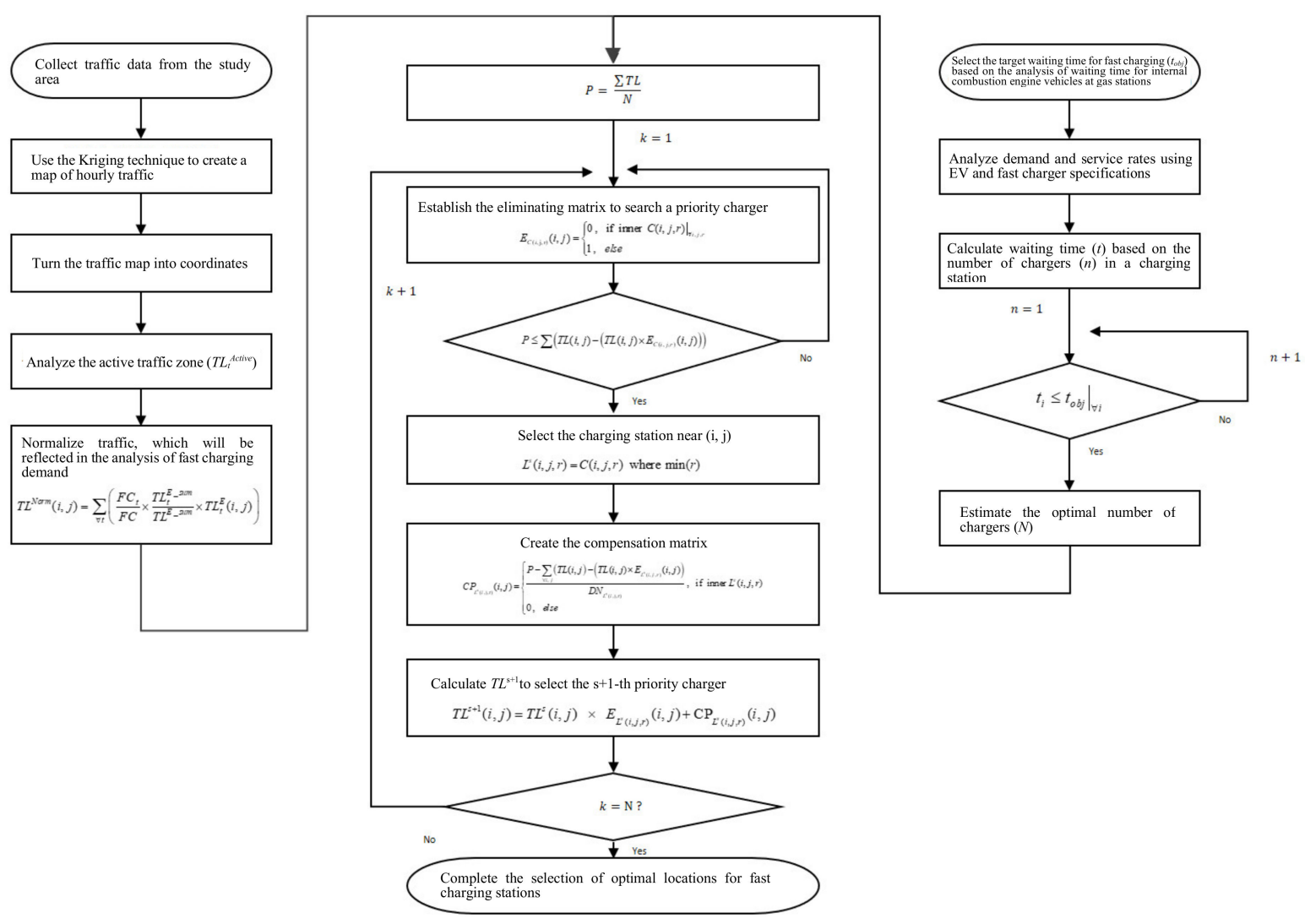

Figure 10. Algorithm used to select the optimal locations of fast charging stations. 


\section{Case Study}

\subsection{Traffic Analysis in Daegu Based on the Kriging Technique}

We conducted a case study of Daegu, Korea, which has the fourth largest population in Korea and the seventh highest per capita income among the 16 local governments in Korea. As such, the number of EVs and amount of EVSE in the city are expected to increase. To simplify the priority fast charger selection process, Dalseo-gu, one of the administrative districts in Daegu, was chosen as the case study area. In total, 96 traffic data collectors are installed in Daegu and record the number of vehicles passing by traffic-data-gathering sections on an hourly basis.

We found that the amount of traffic peaks during the morning and evening rush hours and noticeably decreases after midnight, as in Figure 11. Based on $24 \mathrm{~h}$ traffic data, hourly fast charging patterns were used to determine the optimal traffic level, which was used to determine the expected charging demand.

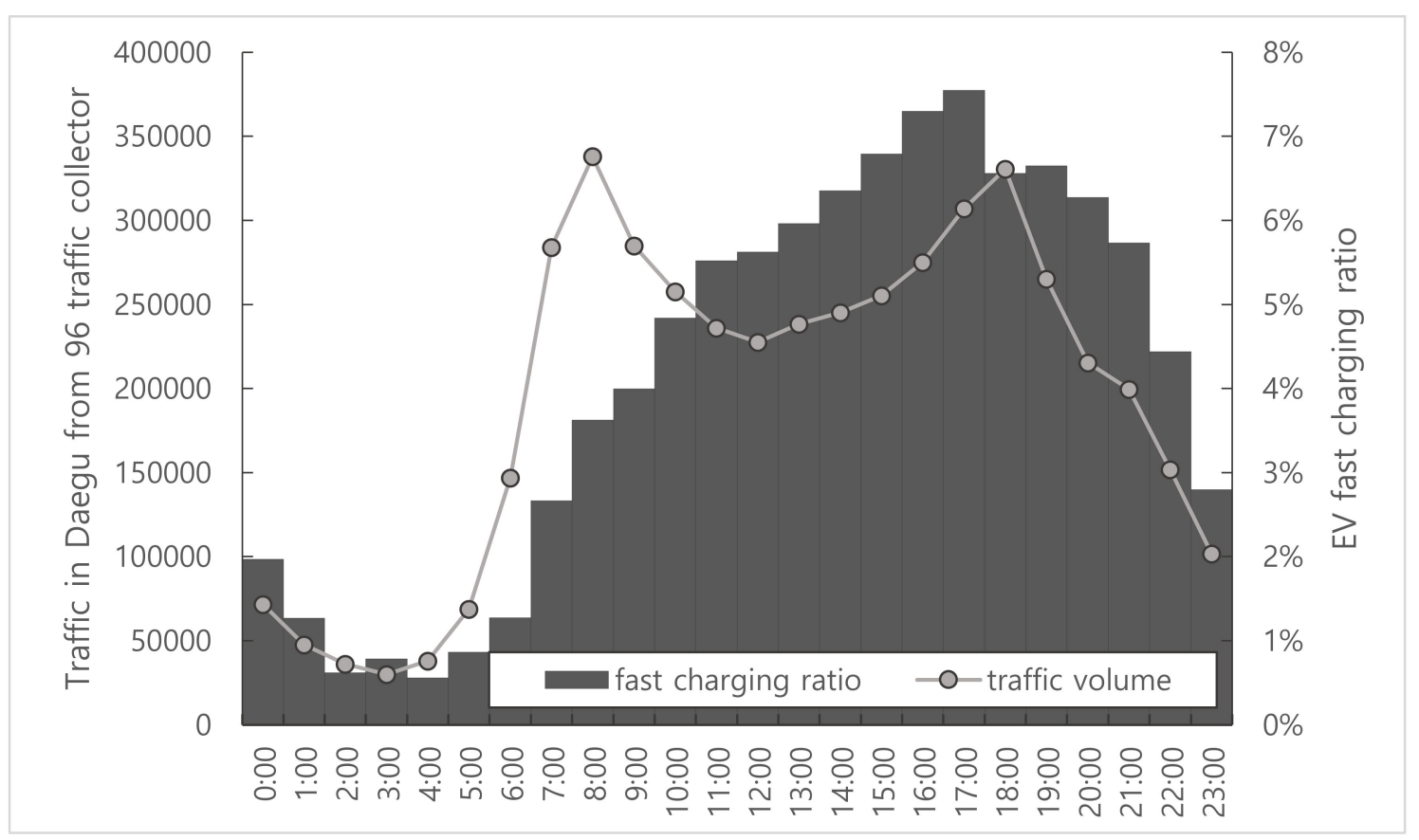

Figure 11. Distribution of fast charging hours and the total hourly traffic in Daegu.

Using 96 traffic data collectors in Daegu, we analyzed the spatial distribution characteristics. By employing the parameters in the empirical variogram, we calculated the theoretical variogram based on the spherical model. We used QGIS, an open-source geographic information system, in this study to visualize the traffic in Daegu. The case study results are presented in Figure 12 [23].

Although this output shows the traffic by zone, this information was used to determine the expected charging demand in this study. 


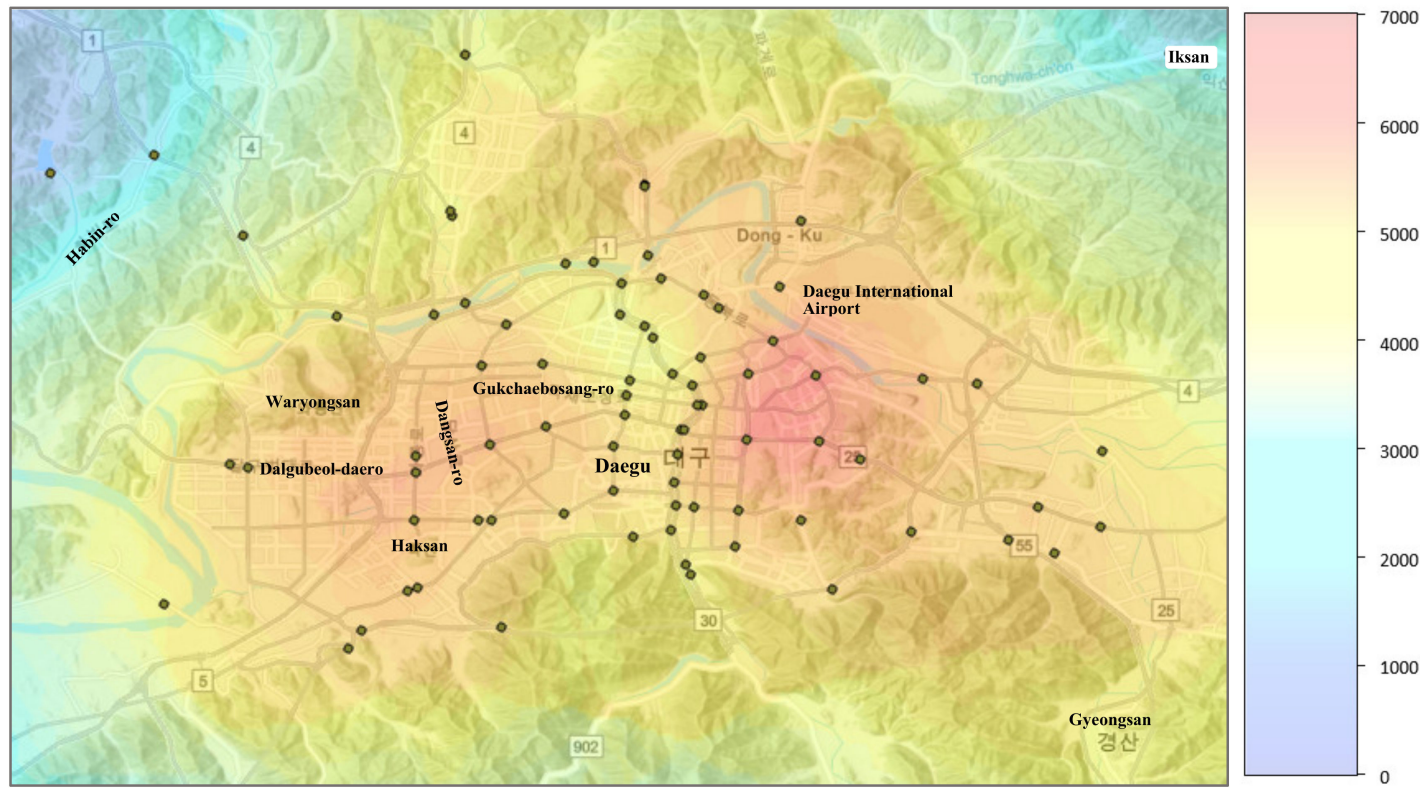

Figure 12. Locations of 96 traffic data collectors and traffic in Daegu visualized by using the Kriging technique.

\subsection{Analysis of the Optimal Number of Chargers Based on the Queueing Model}

The parameter required to use the queueing model was the number of EVs entering the charging station for fast charging per hour. Therefore, the average number of EVs waiting for charging per hour was calculated using the average mileage at full charge and average daily mileage statistics of EVs in Daegu. We utilized the average fuel efficiency and battery capacity of the top seven best-selling EVs in Korea to estimate their average mileage at full charge. Data published by Statistics Korea was employed to estimate the average daily mileage as in the following Table 1:

Table 1. Fuel efficiency and average mileage at full charge by electric vehicle (EV) model.

\begin{tabular}{cccc}
\hline Manufacturer & Model & $\begin{array}{c}\text { Fuel Efficiency } \\
(\mathbf{k m} / \mathbf{k W h})\end{array}$ & $\begin{array}{c}\text { Average Mileage at Full Charge } \\
\mathbf{( k m )}\end{array}$ \\
\hline Hyundai & KONA Electric & 5.6 & 357.9 \\
Hyundai & IONIQ Electric & 6.3 & 177.2 \\
Chevrolet & BOLT EV & 5.5 & 324.8 \\
Kia & NIRO EV & 5.3 & 344.0 \\
Kia & SOUL EV & 5.0 & 158.7 \\
Renault & TWIZY & 7.9 & 80.0 \\
Renault Samsung & SM3 ZE & 4.5 & 168.0 \\
\hline & Average & $\mathbf{5 . 7}$ & $\mathbf{2 3 0 . 1}$ \\
\hline
\end{tabular}

To reflect the traffic in Dalseo-gu, Daegu, we calculated the number of EVs in Dalseo-gu by multiplying the number of EVs in Daegu by the transit rate in Dalseo-gu, as presented in Table 2. 
Table 2. Transit rate by administrative division in Daegu.

\begin{tabular}{cc}
\hline Administrative Division in Daegu & Transit Rrate \\
\hline Jung-gu & 0.025 \\
Dong-gu & 0.152 \\
Seo-gu & 0.049 \\
Nam-gu & 0.048 \\
Buk-gu & 0.239 \\
Suseong-gu & 0.192 \\
Dalseo-gu & 0.294 \\
\hline
\end{tabular}

The number of EVs in Daegu as of March 2019 was 12,763, and EVs account for 1.3\% of all of the vehicles in Daegu. Considering that the transit rate in Dalseo-gu is $29.4 \%$, the number of EVs in Dalseo-gu was calculated to be 3752 , as presentedin Table 3.

Table 3. EV penetration rate and goals in Daegu and Dalseo-gu.

\begin{tabular}{cccc}
\hline Date & $\begin{array}{c}\text { Number of EVs in } \\
\text { Daegu }\end{array}$ & $\begin{array}{c}\text { Number of EVs in } \\
\text { Dalseo-gu }\end{array}$ & $\begin{array}{c}\text { Penetration Rate } \\
\text { (\%) }\end{array}$ \\
\hline Mar 2018 & 2,929 & 861 & 0.3 \\
Mar 2019 & 12,763 & 3,752 & 1.3 \\
2020 (Goal) & 50,000 & 14,700 & 5 \\
2030 (Goal) & 500,000 & 147,000 & 50 \\
\hline
\end{tabular}

We applied the queueing model and conducted a location analysis of fast charging stations established in 20 administrative districts across Dalseo-gu. The number of EVs in each district was approximated based on the proportion of the total Dalseo-gu population contained in the district, and the number of EVs arriving at the fast charging station per hour was calculated as presented in Table 4 .

Table 4. $\lambda$-values analysis of 35 charging stations in Dalseo-gu.

\begin{tabular}{|c|c|c|c|c|c|c|}
\hline & $\begin{array}{l}\text { Administrative } \\
\text { Dong }\end{array}$ & Charging Station & $\begin{array}{l}\text { PercentAge in } \\
\text { Charging }(\%)\end{array}$ & $\begin{array}{c}\text { Sum of } \\
\text { PopulatIon }\end{array}$ & PopulatIon & $\lambda$ \\
\hline 1 & \multirow{2}{*}{ Sindang-dong } & Keimyung College University & \multirow{2}{*}{0.5} & \multirow{2}{*}{36,368} & 18,184 & 1.14 \\
\hline 2 & & Hosan Public Parking Lot & & & 18,184 & 1.14 \\
\hline 3 & \multirow{2}{*}{ Igok 2-dong } & Igok 2-dong Community Center & \multirow{2}{*}{0.5} & \multirow{2}{*}{17,818} & 89,09 & 0.56 \\
\hline 4 & & Seongseo Public Sports Center & & & 89,09 & 0.56 \\
\hline 5 & Igok 1-dong & Vehicle Registration Office West & 1 & 25,235 & 25,235 & 1.59 \\
\hline 6 & \multirow{2}{*}{ Yongsan 2-dong } & Seochon Public Parking Lot & \multirow{2}{*}{0.5} & \multirow{2}{*}{31,262} & 15,631 & 0.98 \\
\hline 7 & & $\begin{array}{c}\text { Yongsan 2-dong Administrative } \\
\text { Welfare Center }\end{array}$ & & & 15,631 & 0.98 \\
\hline 8 & Yongsan 1-dong & SeongseoHomeplus & 1 & 33,319 & 33,319 & 2.10 \\
\hline 9 & \multirow{2}{*}{ Jukjeon-dong } & DaesungUneed Gas Station & \multirow{2}{*}{0.5} & \multirow{2}{*}{15,617} & 7809 & 0.49 \\
\hline 10 & & $\begin{array}{l}\text { Jukjeon-dong Administrative } \\
\text { Welfare Center }\end{array}$ & & & 7809 & 0.49 \\
\hline 11 & \multirow{2}{*}{ Janggi-dong } & Smiling Arts Center & \multirow{2}{*}{0.5} & \multirow{2}{*}{17,491} & 8746 & 0.55 \\
\hline 12 & & Yongsan Station Transfer Parking Lot & & & 8746 & 0.55 \\
\hline 13 & Bolli-dong & $\begin{array}{l}\text { Bolli-dongAdministrative Welfare } \\
\text { Center }\end{array}$ & 1 & 22,991 & 22,991 & 1.45 \\
\hline 14 & Gamsam-dong & e-mart Gamsam & 1 & 28,255 & 28,255 & 1.78 \\
\hline 15 & Duryu 3-dong & Duryu Park Tennis Court & 1 & 9916 & 9916 & 0.62 \\
\hline 16 & \multirow[t]{2}{*}{ Seongdang-dong } & $\begin{array}{l}\text { Seongdang Doosan We've } \\
\text { Apartment }\end{array}$ & \multirow[t]{2}{*}{0.5} & \multirow[t]{2}{*}{25,321} & 12,661 & 0.80 \\
\hline 17 & & Duryu Park Management Office & & & 12,661 & 0.80 \\
\hline
\end{tabular}


Table 4. Cont.

\begin{tabular}{|c|c|c|c|c|c|c|}
\hline & $\begin{array}{l}\text { Administrative } \\
\text { Dong }\end{array}$ & Charging Station & $\begin{array}{l}\text { PercentAge in } \\
\text { Charging }(\%)\end{array}$ & $\begin{array}{c}\text { Sum of } \\
\text { PopulatIon }\end{array}$ & PopulatIon & $\lambda$ \\
\hline 18 & \multirow{3}{*}{$\begin{array}{l}\text { Wolseong } \\
\text { 2-dong }\end{array}$} & $\begin{array}{l}\text { Korea Energy Agency Daegu } \\
\text { Gyeongbuk Office }\end{array}$ & \multirow{3}{*}{0.33} & \multirow{3}{*}{18,962} & 6321 & 0.40 \\
\hline 19 & & Facility Safety Management Office & & & 6321 & 0.40 \\
\hline 20 & & $\begin{array}{c}\text { Daegu Environmental Corporation } \\
\text { (Head Office) }\end{array}$ & & & 6321 & 0.40 \\
\hline 21 & $\begin{array}{l}\text { Wolseong } \\
\text { 1-dong }\end{array}$ & Dalseo-gu Office & 1 & 45,114 & 45,114 & 2.84 \\
\hline 22 & \multirow{2}{*}{ Bon-dong } & Daegu Technical University & \multirow{2}{*}{0.5} & \multirow{2}{*}{14,237} & 7119 & 0.45 \\
\hline 23 & & Daegu BankBolli-dong Office & & & 7119 & 0.45 \\
\hline 24 & $\begin{array}{l}\text { Songhyeon } \\
\text { 2-dong }\end{array}$ & $\begin{array}{c}\text { Songhyeon 2-dongAdministrative } \\
\text { Welfare Center }\end{array}$ & 1 & 20,382 & 20,382 & 1.28 \\
\hline 25 & \multirow{6}{*}{ Jincheon-dong } & Daegu BankWolbae Office & \multirow{6}{*}{0.17} & \multirow{6}{*}{70,222} & 11,704 & 0.74 \\
\hline 26 & & $\begin{array}{l}\text { Jincheon-dongAdministrative } \\
\text { Welfare Center }\end{array}$ & & & 11,704 & 0.74 \\
\hline 27 & & Samsung Raemian 1st Apartment & & & 11,704 & 0.74 \\
\hline 28 & & $\begin{array}{l}\text { Daegu Regional Government } \\
\text { Complex }\end{array}$ & & & 11,704 & 0.74 \\
\hline 29 & & Daegu Arboretum Parking Lot 3 & & & 11,704 & 0.74 \\
\hline 30 & & $\begin{array}{l}\text { DaehanElectric Charging } \\
\text { (Cheonwoo Office) }\end{array}$ & & & 11,704 & 0.74 \\
\hline 31 & Sangin 2-dong & HomplusSangin & 1 & 20,577 & 20,577 & 1.29 \\
\hline 32 & Sangin 1-dong & $\begin{array}{l}\text { Daegu Metropolitan Transit } \\
\text { Corporation }\end{array}$ & 1 & 41,530 & 41,530 & 2.61 \\
\hline 33 & \multirow{2}{*}{ Dowon-dong } & LH Daegu Gyeongbuk Office & \multirow{2}{*}{0.5} & \multirow{2}{*}{39,220} & 19,610 & 1.23 \\
\hline 34 & & $\begin{array}{l}\text { Moonlight Waterside Park Parking } \\
\text { Lot }\end{array}$ & & & 19,610 & 1.23 \\
\hline 35 & Sangin 3-dong & Youth Center Public Parking Lot & 1 & 12,528 & 12,528 & 0.79 \\
\hline
\end{tabular}

Using the calculated $\lambda$ values, we analyzed the waiting time and the number of chargers for 35 charging stations in Dalseo-gu. Consequently, the total number of chargers to satisfy the target waiting time of 5.02 minutes for 35 charging stations in Dalseo-gu, Daegu was calculated as 60, as presented in Table 5. 
Table 5. model for 35 existing fast charging stations (min)..

\begin{tabular}{|c|c|c|c|c|}
\hline Station no. & 1 & 2 & 3 & 4 \\
\hline$\# 1$ & 12.26 & 0.75 & 0.05 & 0.00 \\
\hline$\# 2$ & 12.26 & 0.75 & 0.05 & 0.00 \\
\hline$\# 3$ & 4.59 & 0.18 & 0.01 & 0.00 \\
\hline$\# 4$ & 4.59 & 0.18 & 0.01 & 0.00 \\
\hline$\# 5$ & 22.55 & 0.51 & 0.14 & 0.01 \\
\hline \#6 & 9.70 & 0.55 & 0.04 & 0.00 \\
\hline$\# 7$ & 9.70 & 0.55 & 0.04 & 0.00 \\
\hline \#8 & 46.67 & 2.79 & 0.32 & 0.04 \\
\hline$\# 9$ & 3.90 & 0.13 & 0.00 & 0.00 \\
\hline$\# 10$ & 3.90 & 0.13 & 0.00 & 0.00 \\
\hline \#11 & 4.49 & 0.17 & 0.01 & 0.00 \\
\hline$\# 12$ & 4.49 & 0.17 & 0.01 & 0.00 \\
\hline$\# 13$ & 18.71 & 1.24 & 0.11 & 0.01 \\
\hline \#14 & 29.18 & 1.93 & 0.20 & 0.02 \\
\hline$\# 15$ & 5.21 & 0.22 & 0.01 & 0.00 \\
\hline$\# 16$ & 7.27 & 0.36 & 0.02 & 0.00 \\
\hline$\# 17$ & 7.27 & 0.36 & 0.02 & 0.00 \\
\hline \#18 & 3.08 & 0.09 & 0.00 & 0.00 \\
\hline$\# 19$ & 3.08 & 0.09 & 0.00 & 0.00 \\
\hline$\# 20$ & 3.08 & 0.09 & 0.00 & 0.00 \\
\hline \#21 & 355.00 & 5.77 & 0.77 & 0.11 \\
\hline \#22 & 3.53 & 0.11 & 0.00 & 0.00 \\
\hline \#23 & 3.53 & 0.11 & 0.00 & 0.00 \\
\hline \#24 & 14.88 & 0.95 & 0.08 & 0.01 \\
\hline \#25 & 6.55 & 0.31 & 0.02 & 0.00 \\
\hline \#26 & 6.55 & 0.31 & 0.02 & 0.00 \\
\hline$\# 27$ & 6.55 & 0.31 & 0.02 & 0.00 \\
\hline \#28 & 6.55 & 0.31 & 0.02 & 0.00 \\
\hline$\# 29$ & 6.55 & 0.31 & 0.02 & 0.00 \\
\hline$\# 30$ & 6.55 & 0.31 & 0.02 & 0.00 \\
\hline \#31 & 15.09 & 0.97 & 0.08 & 0.01 \\
\hline$\# 32$ & 133.85 & 4.67 & 0.6 & 0.08 \\
\hline \#33 & 13.90 & 0.88 & 0.07 & 0.00 \\
\hline \#34 & 13.09 & 0.88 & 0.07 & 0.00 \\
\hline \#35 & 7.15 & 0.35 & 0.02 & 0.00 \\
\hline
\end{tabular}

\subsection{Selection of Priority Fast Chargers}

Figure 13 shows the zones in which the traffic data were ignored (shaded regions). The active-traffic zone available for use in the elimination method was converted into a grid of $1000 \times 1086$ cells separated by $18 \mathrm{~m}$, the distance between the nearest fast chargers in Daegu. The expected charging demand for each location was input into each grid cell. 


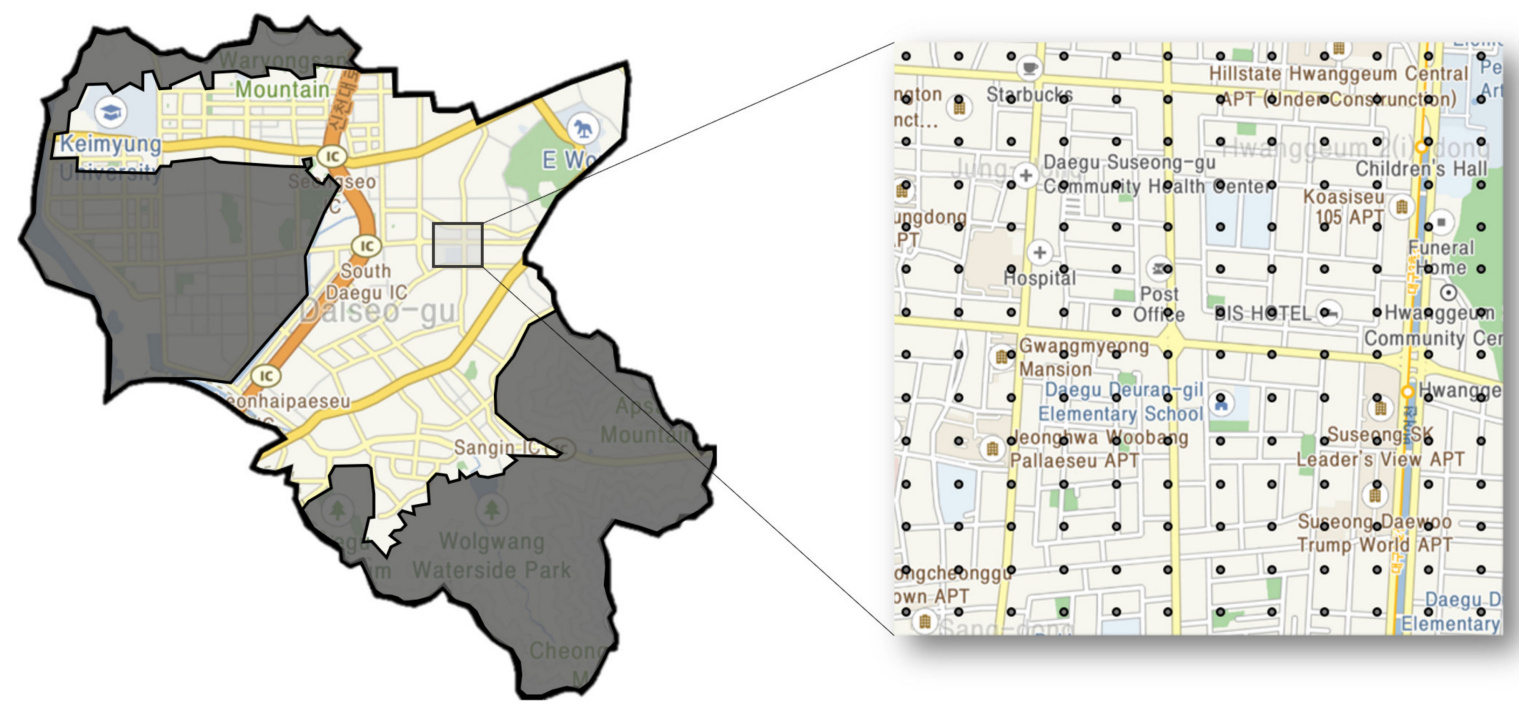

Figure 13. study area represented by non-traffic zones and a grid.

The sum of the amounts of traffic in all of the grid cells indicates the total expected charging demand in Dalseo-gu. The total expected charging demand except for that in the non-traffic zone was calculated to be $17,857,528$, as presented in Table 6 . Considering the optimal number of fast chargers in Dalseo-gu calculated from the queueing model, the expected charging demand that a charger should meet on average $(P)$ was estimated to be 297,625 .

Table 6. Applicable area representation and expected charging demand by traffic zone.

\begin{tabular}{|c|c|c|c|}
\hline & $\begin{array}{l}\text { Total Traffic Volume } \\
\text { in Dalseo-gu }\end{array}$ & $\begin{array}{l}\text { Non-Traffic Zone } \\
\text { in Dalseo-gu }\end{array}$ & $\begin{array}{l}\text { Active-Traffic Zone } \\
\text { in Dalseo-gu }\end{array}$ \\
\hline \multicolumn{4}{|l|}{ Applicable area } \\
\hline Expected charging & $T L^{A}$ & $T L^{U}$ & $T L^{E}$ \\
\hline demand & $35,728,382$ & $17,870,854$ & $17,857,528$ \\
\hline
\end{tabular}

In this case study, the supply range of a charging station for charging demand was set in the form of a circle, assuming charge to be supplied to users who were physically closer to the charging stations. Therefore, the whole study area was searched using the smallest circle to select priority charging stations.

\subsubsection{The Current Status of Installed Fast Chargers}

As of August 2019, there were 44 fast chargers in Dalseo-gu. The aforementioned analysis based on the queueing model suggests that 16 more fast chargers need to be installed. Figure 14 shows the supply range of the expected charging load for the current fast chargers in Dalseo-gu. The TLEM used in this study showed that they could satisfy $60.3 \%$ of the total expected charging demand. 

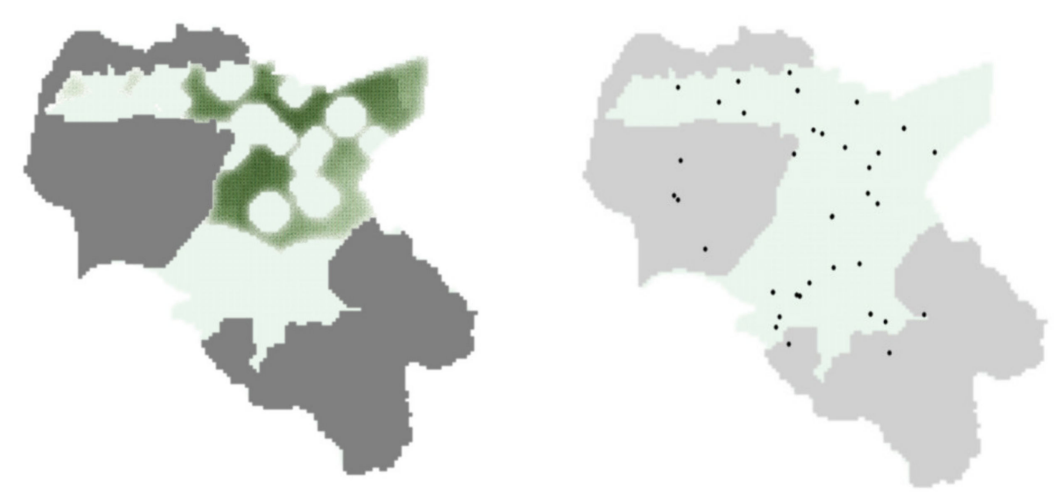

Figure 14. Estimated supply range and locations of the current fast chargers.

The reason that few fast chargers are established in this zone, in which there is a high actual charging demand, seems to be that it is difficult to install enough fast chargers. This may be due to the higher costs of buying or renting land in this area, the fact that many people move around the area with higher charging demand and the commercial value of the area.

\subsubsection{Distribution of Fast Chargers According to TLEM}

For comparison with the current fast chargers, as shown in Figure 15, we performed analyses using the same number of fast chargers in the TLEM. When the TLEM was applied, the chargers could satisfy $64.8 \%$ of the expected charging demand, representing a $4.5 \%$ increase compared with the current number of fast chargers.
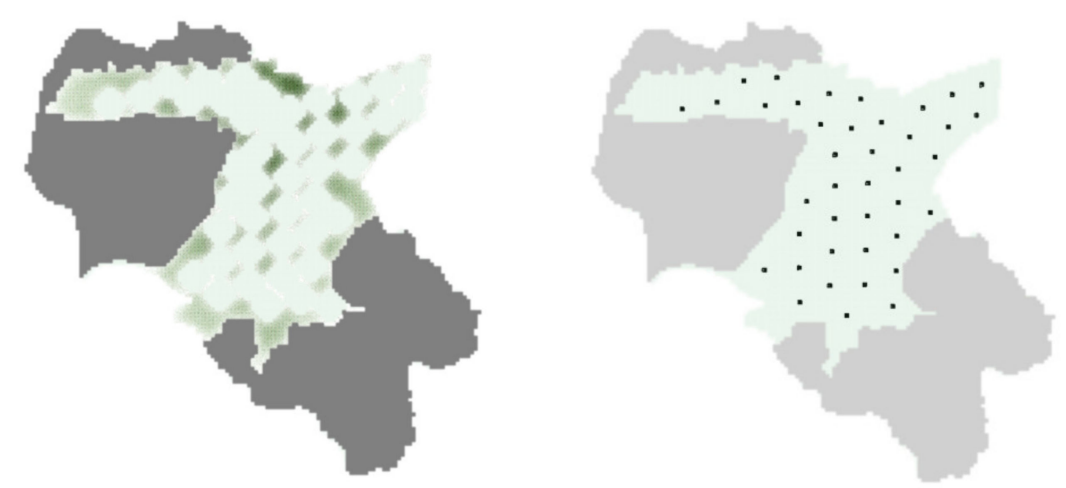

Figure 15. Supply range and locations of 44 fast chargers re-arranged according to the traffic load eliminating method (TLEM).

\subsubsection{Increasing the Number of Fast Chargers Based on the Suggested TLEM}

The increased number of 60 priority fast chargers in Dalseo-gu selected using the elimination method demonstrated that the priority fast chargers could be distributed more evenly as there was not much of a gap in the expected charging demand in Dalseo-gu as presented in Figure 16. Nonetheless, the search radius of the priority chargers selected in the zone with a higher expected charging demand (North) was smaller than that in the zone with a lower expected charging demand (South). Furthermore, these 60 chargers could satisfy the entire expected charging demand in Dalseo-gu. 


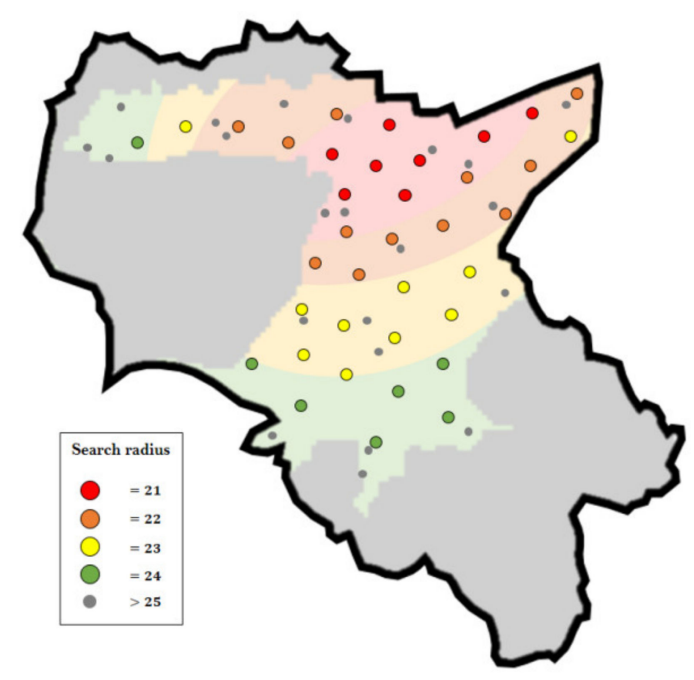

Figure 16. Locations of 60 priority fast chargers selected using the proposed TLEM.

\section{Conclusions}

This report presented an algorithm in which traffic was used to analyze EV charging demand and the installation of chargers in zones with higher charging demands was prioritized. We analyzed traffic data collected in Daegu and demonstrated that the 44 existing fast chargers are densely located in zones with lower traffic; hence, their locations are not ideal. We explained the necessity of conducting a study considering traffic volume. Due to the nature of EV charging infrastructure, it is difficult to relocate charging stations once established. Thus, we selected locations for additional fast chargers, considering the supply ranges of the current chargers. Furthermore, while one charger is usually installed in a charging station in the initial stage of the establishment of fast charging infrastructure, we analyzed a scenario in which multiple chargers were installed in a charging station following the initial stage.

In addition, we identified the average EV waiting time (if sufficient fast charging stations were established) by using the average vehicle waiting time at a gas station. The optimal number of fast chargers required in Dalseo-gu was calculated using the queueing model. We determined the hourly number of EVs chargeable per charging station based on data obtained from Statistics Korea, as well as the EV specifications. If the SOC data of EVs entering charging stations had been available, it would have been possible to produce more realistic outputs from the queueing model.

In this investigation, we selected priority charging stations from a traffic-based urban planning perspective. Based on the locations obtained in this study, we will verify the priority charging station selections from the perspective of the electric power system in a planned follow-up study [24,25].

Author Contributions: Conceptualization, methodology and validation, B.-G.C. and B.-C.O.; software, formal analysis and writing-original draft preparation, B.-G.C.; resources, visualization and data curation, S.C.; writing - review and editing, B.-G.C. and S.-Y.K.; supervision, project administration and funding acquisition, S.-Y.K.; All authors have read and agreed to the published version of the manuscript.

Funding: This study was supported by a research grant for 2016 Basic Research and Development Projects selected by Korea Electric Power Corporation (project number: R17XA05-47).

Conflicts of Interest: The authors declare no conflict of interest. 


\section{Nomenclature}

\begin{tabular}{|c|c|}
\hline$T L_{t}^{A}$ & Total traffic in the study area \\
\hline$T L_{t}^{U}$ & Traffic in the non-traffic zone in the study area \\
\hline$T L_{t}^{E}$ & Expected traffic in the study area \\
\hline$T L_{t}^{\text {Norm }}$ & Normalized traffic \\
\hline$F C_{t}$ & Hourly fast charging pattern \\
\hline$T L$ & Total expected charging demand in the study area \\
\hline$n_{i}$ & Number of fast chargers at the $i$-th charging station \\
\hline$N$ & Total number of fast chargers in the study area \\
\hline$t_{o b j}$ & $\begin{array}{l}\text { Target waiting time for electric vehicles at the fast charging } \\
\text { station }\end{array}$ \\
\hline$t_{i}$ & $\begin{array}{l}\text { Waiting time for electric vehicles at the } i \text {-th charging } \\
\text { station }\end{array}$ \\
\hline$\lambda$ & $\begin{array}{l}\text { Hourly number of electric vehicles arriving at the fast } \\
\text { charging station }\end{array}$ \\
\hline$s$ & Number of chargers at the charging station \\
\hline$\mu$ & Hourly number of electric vehicles chargeable \\
\hline$\rho$ & User rate at fast charging station \\
\hline$n$ & Number of users in the charging station \\
\hline$P_{0}$ & Probability of no users at the charging station \\
\hline$L_{q}$ & Average number of users at the charging station \\
\hline$W_{q}$ & Average time spent at the charging station \\
\hline$P$ & Expected average charging demand for a charger \\
\hline$C(i, j, r)$ & Search circle with $(i, j)$ at the center and $r$ a sradius \\
\hline$E_{C(i, j, r)}(i, j)$ & $\begin{array}{l}\text { Eliminating matrix with } 0 \text { being a point in the search circle } \\
\text { and } 1 \text { being a point outside the circle }\end{array}$ \\
\hline$L^{s}(i, j, r)$ & $\begin{array}{l}\text { Optimal location of the s-th charging station with }(i, j) \text { at } \\
\text { the center and } r \text { as radius }\end{array}$ \\
\hline$D N_{L^{s}(i, j, r)}$ & Number of points in $L^{s}$ \\
\hline$C P_{L^{s}(i, j, r)}(i, j)$ & Compensation value for fast charging demand \\
\hline
\end{tabular}

\section{References}

1. Clairand, J.M.; Guerra-Terán, P.; Serrano-Guerrero, X.; González-Rodríguez, M.; Escrivá-Escrivá, G. Electric Vehicles for Public Transportation in Power Systems: A Review of Methodologies. Energies 2019, $12,3114$. [CrossRef]

2. Kong, C.; Jovanovic, R.; Bayram, I.; Devetsikiotis, M. A Hierarchical Optimization Model for a Network of Electric Vehicle Charging Stations. Energies 2017, 10, 675. [CrossRef]

3. Canizes, B.; Soares, J.; Costa, A.; Pinto, T.; Lezama, F.; Novais, P.; Vale, Z. Electric Vehicles' User Charging Behaviour Simulator for a Smart City. Energies 2019, 12, 1470. [CrossRef]

4. Qiao, Y.; Huang, K.; Jeub, J.; Qian, J.; Song, Y. Deploying Electric Vehicle Charging Stations Considering Time Cost and Existing Infrastructure. Energies 2018, 11, 2436. [CrossRef]

5. Chen, L.; Chen, Z.; Huang, X.; Jin, L. A Study on Price-Based Charging Strategy for Electric Vehicles on Expressways. Energies 2016, 9, 385. [CrossRef]

6. Ji, Z.; Huang, X. Plug-in electric vehicle charging infrastructure deployment of China towards 2020: Policies, methodologies, and challenges. Renew. Sustain. Energy Rev. 2018, 90, 710-727. [CrossRef]

7. Lin, Y.; Zhang, K.; Shen, Z.J.M.; Miao, L. Charging Network Planning for Electric Bus Cities: A Case Study of Shenzhen, China. Sustainability 2019, 11, 4713. [CrossRef]

8. Palmer, D.; Cole, I.; Betts, T.; Gottschalg, R. Interpolating and Estimating Horizontal Diffuse Solar Irradiation to Provide UK-Wide Coverage: Selection of the Best Performing Models. Energies 2017, 10, 181. [CrossRef]

9. Cinti, D.; Procesi, M.; Poncia, P. Evaluation of the Theoretical Geothermal Potential of Inferred Geothermal Reservoirs within the Vicano-Cimino and the Sabatini Volcanic Districts (Central Italy) by the Application of the Volume Method. Energies 2018, 11, 142. [CrossRef] 
10. Cheon, S.; Kang, S.J. An Electric Power Consumption Analysis System for the Installation of Electric Vehicle Charging Stations. Energies 2017, 10, 1534. [CrossRef]

11. Wu, Y.; Xie, C.; Xu, C.; Li, F. A Decision Framework for Electric Vehicle Charging Station Site Selection for Residential Communities under an Intuitionistic Fuzzy Environment: A Case of Beijing. Energies 2017, 10, 1270. [CrossRef]

12. Wu, Y.; Yang, M.; Zhang, H.; Chen, K.; Wang, Y. Optimal Site Selection of Electric Vehicle Charging Stations Based on a Cloud Model and the PROMETHEE Method. Energies 2016, 9, 157. [CrossRef]

13. Liu, G.; Kang, L.; Luan, Z.; Qiu, J.; Zheng, F. Charging Station and Power Network Planning for Integrated Electric Vehicles (EVs). Energies 2019, 12, 2595. [CrossRef]

14. Micari, S.; Polimeni, A.; Napoli, G.; Andaloro, L.; Antonucci, V. Electric vehicle charging infrastructure planning in a road network. Renew. Sustain. Energy Rev. 2017, 80, 98-108. [CrossRef]

15. Yi, T.; Cheng, X.B.; Zheng, H.; Liu, J. Research on Location and Capacity Optimization Method for Electric Vehicle Charging Stations Considering User's Comprehensive Satisfaction. Energies 2019, 12, 1915. [CrossRef]

16. Cui, S.; Zhao, H.; Zhang, C. Locating Charging Stations of Various Sizes with Different Numbers of Chargers for Battery Electric Vehicles. Energies 2018, 11, 3056. [CrossRef]

17. Zhao, H.; Li, N. Optimal Siting of Charging Stations for Electric Vehicles Based on Fuzzy Delphi and Hybrid Multi-Criteria Decision Making Approaches from an Extended Sustainability Perspective. Energies 2016, 9, 270. [CrossRef]

18. Motoaki, Y. Location-Allocation of Electric Vehicle Fast Chargers-Research and Practice. WEVJ 2019, 10, 12. [CrossRef]

19. Akbari, M.; Brenna, M.; Longo, M. Optimal Locating of Electric Vehicle Charging Stations by Application of Genetic Algorithm. Sustainability 2018, 10, 1076. [CrossRef]

20. Wu, H.; Niu, D. Study on Influence Factors of Electric Vehicles Charging Station Location Based on ISM and FMICMAC. Sustainability 2017, 9, 484. [CrossRef]

21. Guo, C.; Yang, J.; Yang, L. Planning of Electric Vehicle Charging Infrastructure for Urban Areas with Tight Land Supply. Energies 2018, 11, 2314. [CrossRef]

22. Nam, S.; Hur, J. Probabilistic Forecasting Model of Solar Power Outputs Based on the Naïve Bayes Classifier and Kriging Models. Energies 2018, 11, 2982. [CrossRef]

23. Alegre, S.; Míguez, J.V.; Carpio, J. Modelling of electric and parallel-hybrid electric vehicle using Matlab/Simulink environment and planning of charging stations through a geographic information system and genetic algorithms. Renew. Sustain. Energy Rev. 2017, 74, 1020-1027. [CrossRef]

24. Choi, B.R.; Lee, W.P.; Won, D.J. Optimal Charging Strategy Based on Model Predictive Control in Electric Vehicle Parking Lots Considering Voltage Stability. Energies 2018, 11, 1812. [CrossRef]

25. Han, H.S.; Oh, E.; Son, S.Y. Study on EV Charging Peak Reduction with V2G Utilizing Idle Charging Stations: The Jeju Island Case. Energies 2018, 11, 1651. [CrossRef] 